\title{
The Blue Swimming Crab Fishers and Fishing Practices in Leyte and Samar, Philippines
}

\author{
Margarita T. de la Cruz ${ }^{\star 1}$, John O. de la Cruz ${ }^{1}$, Elyrose Kim C. Ruizo ${ }^{1}$, Irene L. Tan ${ }^{1}$ \\ ${ }^{1}$ University of the Philippines Visayas Tacloban College, Magsaysay Blvd., Tacloban City, Leyte
}

\begin{abstract}
A B S T R A C T
Blue swimming crab (BSC) industry contributes considerably to the region's economy. Despite the extensive harvesting and marketing activities, there is no information on the people who make a living out of the BSC resource. This study provides suggestions to improve the management of BSC fishery by looking into the crabbers' socio-demographic profile, crabbing gears, crabbing practices, and awareness of regulatory measures regarding BSC fishery management. Semi-structured interviews were conducted from April to August 2014 in selected crabbing municipalities in five major fishing grounds of Eastern Visayas. Generally, the income of the crabbers and their family is way below the poverty threshold indicated for Eastern Visayas. This condition is aggravated by the lack of formal education among the crabbers and their members, which limits them from engaging in other livelihood opportunities. The marginal contribution from other livelihood sources to the household income is still insufficient to support other needs, particularly education. To increase the daily catch, crabbers resorted to unsustainable and destructive crabbing practices, which depletes further the resources. To address these issues, LGUs in partnership with other concerned organizations should formulate and implement programs and projects that will alleviate the living conditions of the crabbers. Moreover, the LGUs should implement national plans along with local legislation to ensure the regulation of BSC catching and selling. Crabbers must practice sustainable, cost-effective, and non-destructive crabbing activity to improve BSC production. Further studies into the biology, seasonality, and stock assessment are needed to craft appropriate science-based management framework.
\end{abstract}

E-mail address: cruzmarge2003@yahoo.com*

Received: August 13, 2018; Accepted: October 9, 2018
Keywords: Blue Swimming Crab, Crabbers, Fishing Practices

\section{I N T R O D U C T I O N}

B lue swimming crab (BSC), Portunus pelagicus, is one of the most important crab species in the Philippines as well as in other countries in the tropics due to its increasing global demand (Lai et al. 2010; FAO 2013). The BSC production amounted to 5,923.67 MT which contributed 0.01\% to the total Philippine fisheries production in the first quarter of 2018 (PSA 2018). Ninety-three percent of the BSC production, 5,507.53 MT, (PSA 2018) came from municipal capture fisheries making it a major component of the municipal or small-scale fishery in the country. Based on a survey in Eastern Visayas, De la Cruz et al. (2015) identified Ormoc City, Dulag, Tanauan, and Tacloban City in Leyte; Marabut, Basey, Villareal, San Sebastian, Daram, Zumarraga, and Catbalogan in Samar; and Mercedes, Salcedo, Quinapondan, and Guiuan in Eastern Samar as topranking sources of BSC in terms of estimated volume of catch. Most of the crabbers in the said coastal towns catch BSC year-round. These crabbing municipalities supply six crab meat-picking plants operating in the region, employing mostly women meat pickers (De la Cruz et al. 2015).

The BSC fishery is a multi-gear activity. Crabbers are usually artisanal and capture crabs by gleaning, use of bamboo traps, crab lift nets (Gadhavi et al. 2013; Romero et al. 2009), crab pots, and gill nets (Del Norte-Campo et al. 2004; Ingles 2004; Germano and Melgo 2003). Crab pots are known to catch largesized crabs compared to bottom-set gill nets. On the other hand, the sheer fishing pressure of daily catching and the lack of implementation of management measures lead to overfishing. Moreover, other gears like trawl, which is banned in the coastal waters seven fathoms deep and seven kilometers from the shoreline, are still used in many areas.

Given the importance of the industry to the region, and the need to improve the lives of the 
crabbers, it is urgent for the government to establish and implement conservation measures for the industry's sustainability. At the same time, an in-depth study of the crabbers should provide policymakers with a clearer understanding of this sector of the fishing industry.

This study describes the sociodemographic profile of the crabbers in Eastern Visayas. Most importantly, this study provides suggestions to improve the

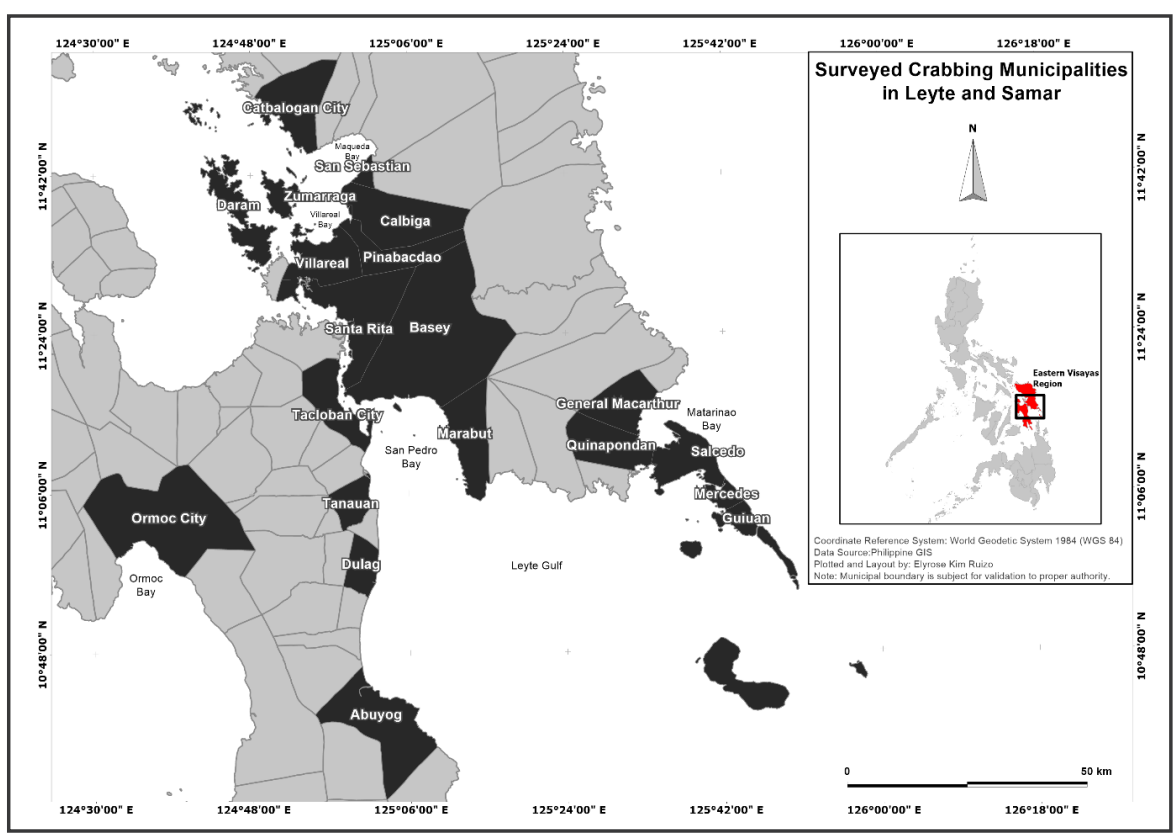

Figure 1. Map of surveyed crabbing municipalities in Leyte and Samar management of BSC fishery by looking into the crabbers' gears, crabbing practices, and awareness of regulatory measures regarding catching and selling BSC in the region.

\section{MATERIALS AND METHODS}

A survey of the crabbers from different crabbing municipalities along the different fishing grounds in Eastern Visayas (Table 1) was conducted from April to August 2014. Based on the list by Germano et al. (2003) and De la Cruz et al. (2015), 24 crabbing municipalities were visited to determine the extent of crabbing activities in the area. However, only 20 municipalities (Table 1) were finally considered for the study since no full-time or part-time crabbers were identified in the municipalities of Matalom, Carigara, Palompon, and Barugo. The BSC landed in these areas are caught (bycatch) along with target species such as squids, shrimps, and other economically important fish species using bottom trawls, sayad, liba-liba, and fish corral, among others. According to the locals, there has been a significant decline in the catch of BSC over the years, particularly in Carigara (De la Cruz et al. 2015), which led the fishers to other livelihood opportunities.

The survey included individual fishers who engaged in crabbing activities either as part-time or full-time. Crabbers are considered full-time when they catch BSC throughout the year and the bulk of the family income comes from crabbing. On the other

hand, part-time crabbers include those who operate only during peak season and shift to other livelihood activities during lean months. Lean months and peak months varies across the different fishing grounds in the region and changes depending on the prevalence of typhoons. The number of crabbing villages or barangays selected for this study varied from one municipality to the other. Factors considered in selecting the crabbing villages in each town include the accessibility of the crabbing barangay; the aggregate volume of BSC catch in each barangay; and the number of crabbing villages. The top two or three barangays with the highest volume of BSC catch in municipalities with less than or equal to five crabbing villages were selected for the survey. In municipalities where there were more than five crabbing villages, those with the highest contribution to the BSC production were selected. During the survey period, ethnographic interviews, using a semi-structured survey instrument, were conducted on full-time and part-time crabbers who are available and willing to participate in the study. The instrument includes information on the crabber's socio-economic profile, namely age, sex, civil status, educational attainment, number of dependents, and average monthly income from crabbing. For the gear preference and crabbing practices, each crabber was asked the following: type of gear used or preferred; dimension or number of units of the gear; soaking time of gears; the frequency of crabbing; bait used, if any; and companion in 
Table 1. List of crabbing municipalities surveyed along the different fishing grounds in Eastern Visayas (2014)

\begin{tabular}{|l|l|l|}
\hline Fishing Ground & \multicolumn{1}{|c|}{ Municipality/City } & \multicolumn{1}{c|}{ Province } \\
\hline Ormoc Bay & Ormoc City & Leyte \\
\hline Leyte Gulf & Abuyog & Leyte \\
\hline & Dulag & Leyte \\
\hline & Guiuan & Eastern Samar \\
\hline & Mercedes & Eastern Samar \\
\hline & Salcedo* & Eastern Samar \\
\hline Matarinao Bay & Quinapondan* & Eastern Samar \\
\hline & Quinapondan & Eastern Samar \\
\hline & Gen. MacArthur & Eastern Samar \\
\hline San Pedro Bay & Marabut & Samar \\
\hline & Basey & Samar \\
\hline & Sta. Rita & Samar \\
\hline & Tacloban City & Leyte \\
\hline & Tanauan & Leyte \\
\hline & Catbalogan City & Samar \\
\hline Maqueda Bay & San Sebastian & Samar \\
\hline & Calbiga & Samar \\
\hline & Pinabacdao & Samar \\
\hline & Villareal & Samar \\
\hline & Daram & Samar \\
\hline & Zumarraga & Samar \\
\hline
\end{tabular}

Note: ${ }^{*}$ - Some of the crabbing barangays of Salcedo and Quinapondan are situated in the coast lining Matarinao Bay while other fishing villages of the said towns are located in Leyte Gulf.

crabbing. In terms of awareness on BSC fishery management, the respondents were asked about what type of problems and concerns related to crabbing they are experiencing, knowledge on any government or non-government regulatory measures to manage the BSC resource, and suggestions to address their problems and concerns and to better manage the resources.

\section{RESULT S A N D I S CUSSION}

\subsection{BSC fishers' socio-demographic profile}

Based on the information obtained from the middlemen, traders from buying stations, and crab meat-picking plants, there are over 2,000 crabbers in the region but only 704 respondents participated in the survey. Table 2 provides the distribution of crabbers by age, sex, civil status, and educational attainment. Of the crabbers interviewed, 292 (42\%) are full-time while $412(58 \%)$ are part-time, which is dominated by menfolk (98.6\%) who are mostly married (89\%). Very few women engage in the trade $(1.4 \%)$ either as companion fisher $(62 \%)$ or as solo crabbers $(38 \%)$. Majority of the crabbers $(56.5 \%)$ belong to the middle-aged group (31-50 years old) while 20.5\% of the respondents are young, belonging to $\leq 30$-age bracket. Most crabbers attended elementary education (55\%) but only $52 \%$ of them were able to graduate. In Matarinao Bay, $27 \%$ of the crabbers do not have formal education, relatively the highest proportion among non-educated crabbers in the surveyed areas. Postelementary education is relatively higher in Leyte Gulf crabbing municipalities where $26 \%$ of the crabbers were able to attend secondary education and $12 \%$ were able to earn their diplomas. Moreover, college level $(7.5 \%)$ and graduates $(0.9 \%)$ were observed to participate in the industry as crabbers. Crabbers claim that they can earn as much as PHP $1,500.00$ on the average in one crabbing operation during peak season 
Table 2. Distribution of full-time and part-time crabbers

by age, sex, civil status, and educational attainment

\begin{tabular}{|c|c|c|c|c|c|c|}
\hline \multirow[t]{2}{*}{ Respondents (704) } & \multicolumn{2}{|c|}{ Fulltime (292) } & \multicolumn{2}{|c|}{ Part-time (412) } & \multirow{2}{*}{$\begin{array}{c}\text { TOTAL } \\
\text { No. }\end{array}$} & \multirow[t]{2}{*}{$\%$} \\
\hline & No. & $\%$ & No. & $\%$ & & \\
\hline \multicolumn{7}{|l|}{ Age } \\
\hline \multicolumn{7}{|l|}{ Male (694) } \\
\hline$\leq 30$ & 63 & 22.0 & 80 & 19.7 & 143 & 20.6 \\
\hline $31-50$ & 157 & 54.7 & 233 & 57.2 & 390 & 56.2 \\
\hline $51-70$ & 65 & 22.6 & 88 & 21.6 & 153 & 22.0 \\
\hline$>70$ & 2 & 0.7 & 6 & 1.5 & 8 & 1.2 \\
\hline \multicolumn{7}{|l|}{ Female (10) } \\
\hline$\leq 30$ & 1 & 25.0 & & 0.0 & 1 & 10.0 \\
\hline $31-50$ & 3 & 75.0 & 5 & 100.0 & 8 & 80.0 \\
\hline $51-70$ & 1 & 25.0 & & 0.0 & 1 & 10.0 \\
\hline \multicolumn{7}{|l|}{ Sex ratio } \\
\hline Male & 287 & 98.3 & 407 & 98.8 & 694 & 98.6 \\
\hline Female & 5 & 1.7 & 5 & 1.2 & 10 & 1.4 \\
\hline \multicolumn{7}{|l|}{ Civil Status } \\
\hline \multicolumn{7}{|l|}{ Male } \\
\hline Single & 30 & 10.5 & 40 & 9.8 & 70 & 10.1 \\
\hline Married & 254 & 88.5 & 365 & 89.7 & 619 & 89.2 \\
\hline Widow & 3 & 1.0 & 0 & 0 & 3 & 0.4 \\
\hline Seperated & 0 & 0.0 & 2 & 0.5 & 2 & 0.3 \\
\hline \multicolumn{7}{|l|}{ Female } \\
\hline Married & 4 & 80 & 5 & 100 & 9 & 90.0 \\
\hline Widowed & 1 & 20 & & & 1 & 10.0 \\
\hline \multicolumn{7}{|l|}{ Educational Attainment } \\
\hline \multicolumn{7}{|l|}{ Male } \\
\hline No Schooling & 20 & 7.0 & 26 & 6.4 & 46 & 6.6 \\
\hline Elementary Level & 83 & 28.9 & 94 & 23.1 & 177 & 25.5 \\
\hline Elementary Graduate & 81 & 28.2 & 135 & 33.2 & 216 & 31.1 \\
\hline High School Level & 52 & 18.1 & 74 & 18.2 & 126 & 18.2 \\
\hline High School Graduate & 36 & 12.5 & 52 & 12.8 & 88 & 12.7 \\
\hline College Level & 13 & 4.5 & 22 & 5.4 & 35 & 5.0 \\
\hline College Graduate & 2 & 0.7 & 4 & 1.0 & 6 & 0.9 \\
\hline Female & 1 & 20.0 & 1 & 20.0 & 2 & 20.0 \\
\hline Elementary Level & 2 & 40.0 & & 0.0 & 2 & 20.0 \\
\hline Elementary Graduate & 1 & 20.0 & 2 & 40.0 & 3 & 30.0 \\
\hline High School Level & & 0.0 & 2 & 40.0 & 2 & 20.0 \\
\hline High School Graduate & 1 & 20.0 & & 0.0 & 1 & 10.0 \\
\hline College Level & & & & & & \\
\hline
\end{tabular}


even if BSC price drops due to high stock volume. However, these earnings would suddenly drop to PHP 350.00 during lean months despite the higher price of BSC in the market. In BSC wild stock depleted areas, like in Ormoc Bay, income for the crabbers remain low on both seasons. Other sources of livelihood for parttime crabbers include fishing (77\%), both shrimping and fishing (5\%), shrimping (2\%), gleaning (2\%), farming and upland cultivation (2\%), and other (11\%) activities such as construction, and carpentry, among others. The average size of the crabbing families in Eastern Visayas is five. Crabbing families earn an average of PHP 4,702.00 per month. On the average, crabbers support three dependents per household. In particular, crabbers from Ormoc Bay and Leyte Gulf support two to nine members, one to six dependents for each household head in Matarinao Bay, while San Pedro Bay crabbers support one to ten dependents. The crabbers with the highest number of dependents come from Maqueda Bay, supporting one to 18 household members.

According to the Philippine Statistics Authority (2016), the monthly poverty threshold for a family of five in Eastern Visayas in 2015 is estimated to be at PHP 8,877.00. This represents the average amount needed to meet the family's basic food and non-food requirements. The study revealed that the average income of the crabbing household is way below the indicated poverty threshold for Eastern Visayas. Likewise, the income of the crabbers varies depending on the season. Crabbers claim that their income has significantly declined after super typhoon Haiyan hit the region in 2013 making it difficult for them to meet the family's basic needs. Furthermore, the crabbers admitted that a greater portion of their income is allocated for the important daily necessities such as food, water, maintenance of their gears, and clothing, leaving behind education and other needs. Additionally, crabbing families usually sacrifice the education of their children so they can help provide additional income to meet the most basic needs of the family. Though some of the crabbers engage in other livelihood opportunities, the marginal contribution from these earnings to the household income is still inadequate to supplement the basic and other needs of the family. Other sources of income are needed for the crabbing families to live a decent life. Many crabbers would, in fact, sell all their catch and buy low-cost food for their family.

About one-third of the population in Eastern Visayas depends on agriculture and fishery for their livelihood (PSA 2016). According to ACTED (2014), families getting most of their income from fishing, coconut cultivation, other upland cultivation such as banana and sugarcane, and agriculture-related trading have no regular income and are seeking for more ways to sustain their livelihoods. This situation holds true for the crabbers who have more household dependents. It is for this reason that some crabbers shift from one type of livelihood to the other, or engage in multiple-income generating activities hoping that this particular strategy will help improve their economic status. However, the earning population who are dependent on agriculture and fisheries in Eastern Visayas are still experiencing low land productivity and gross value added (GVA) due to inadequate infrastructure support, weak market linkages, poor financial capability of agricultural workers, low technology adaptation, and vulnerability to climate change, among others (Meniano 2016).

Education takes a back seat among the fishing families in general due to poverty. In a study by the Asian Development Bank (2009), the poor remain poor in the Philippines because they cannot borrow against future earnings to invest in education, skills, new crop, and other entrepreneurial activities. Thus, the children of crabbers and some fishers with no formal schooling admit that they have no choice but to participate in the BSC fishery as full-time crabbers. Moreover, the lack of education confines these crabbers to this type of livelihood, creating pressures on the crab population, and contributing to resource depletion. The lack of formal education beyond high school severely limits alternative employment opportunities (Rhodes et al. 2001) due to skills mismatch in the labor market, a lack of labor market information available to young people, and insufficient employment services for atrisk youth (ADB 2018). In 2016, 48.4\% were in the 15-24 age group, $31.2 \%$ were high school graduates, and $21.4 \%$ were college graduates of roughly 2.4 million unemployed people (PSA 2016). However, the educational attainment of the crabbers is independent of their fate of being part-time or full-time.

The recruitment of crabbers in Leyte and Samar start at an early age. Boys as young as seven years old accompany their parents or relatives in crabbing and eventually operate as individual crabber upon learning the BSC fishing practices and trade. In the region, it is a common practice by crabbing parents to bring their children to the sea to introduce and expose the young individuals to the type of livelihood they practice. Over time, the children learn the techniques and become expert crabbers themselves. Crabbers over 70 years old still practice the trade to support 
Table 3. Distribution and percentage of boat type used by the crabbers

\begin{tabular}{|c|c|c|c|c|}
\hline \multirow{2}{*}{$\begin{array}{c}\text { Fishing ground } \\
\text { (Respondents) }\end{array}$} & \multicolumn{4}{|c|}{ Boat type } \\
\cline { 2 - 5 } & \multicolumn{2}{|c|}{ Motorized } & Non-motorized \\
\cline { 2 - 5 } & No. & $\%$ & No. & $\%$ \\
\hline Ormoc Bay (19) & 10 & 53 & 9 & 47 \\
\hline San Pedro Bay (199) & 163 & 82 & 36 & 18 \\
\hline Leyte Gulf (195) & 170 & 87 & 25 & 13 \\
\hline Matarinao Bay (41) & 31 & 76 & 10 & 24 \\
\hline Maqueda Bay (250) & 111 & 44 & 139 & 56 \\
\hline TOTAL (704) & $\mathbf{4 8 5}$ & $\mathbf{6 9}$ & $\mathbf{2 1 9}$ & $\mathbf{3 1}$ \\
\hline
\end{tabular}

themselves and in some cases, some members of the family. The age of the crabbers from the different fishing grounds are not significantly different.

In Eastern Visayas, women play an important role in the household of crabbing families. In general, the role of women in fisheries include fishing, catch marketing or vending, fish processing, and net mending, among others (Siason 2004). Moreover, in some areas, some women are not allowed to go fishing or crabbing for certain cultural reasons or belief. Very few women have genuine desire to go fishing anyway, a situation common in Southeast Asia (Butcher 2004). Women who are not involved in the BSC fishery are engaged in other activities such as looking for an alternative livelihood, tending to household duties, and cultivating farm crops (Cabrales et al. 2015), among others, to supplement the basic needs of the family. Moreover, this study showed that women in Eastern Visayas also participate in subsistence fisheries by gleaning on reef flats, mangroves, and seagrass beds; and fishing within municipal waters. Though most of the catch is utilized for the household consumption, some of the gleaned seafood are sold to local markets and direct consumers. However, the contribution of gleaning to the household income is generally low not just among the crabbing families in the region but in other coastal communities in the country as well (De Guzman et al. 2016). Men are responsible for providing the income for the household, but women contribute considerably to the household income (ACTED 2014). This is how labor is generally distributed among the male and the female population of BSC fishers, although there are cases where women also become full-time crabbers themselves to support their needs and those of their families.

\subsection{Crabbing gears and practices}

About $69 \%$ of the surveyed crabbers use motorized boats in crabbing (Table 3 ). The relatively high percentage of motorized boats in the region can be attributed to the aid extended by NGOs and government agencies to the survivors of ST Haiyan. Boats made from fiberglass and traditional wooden crafts were distributed throughout the region, particularly in areas severely affected by the super typhoon. The motorboat engines range from 4 to 7 horsepower. However, this assistance may also have detrimental effects on the fishery as it can result in increased fishing pressure in an already damaged ecosystem. In fact, crabbers claim that they are already experiencing low catches. Meanwhile, assistance coming from government and other concerned organizations must be thoroughly studied and planned so as to avoid negative effects on the environment and the social and economic condition of the crabbers.

Crabbers use crab pots, crab lift nets, and bottom-set gill nets in the BSC fishing activities in Leyte and Samar. These are also the same gears reported by Germano and Melgo (2003). Other gears such as trawl, spears, beach seine, and fish corral were also operated in the region (Germano and Melgo 2003). Some crabbers claimed and are concerned that trawls are still operating in Maqueda Bay that sometimes destroys their bottom-set gill nets. They claim that they cannot do anything about it although they know that trawl operation in the bay is illegal. Trawl operation is banned in waters less than seven fathoms deep and within seven kilometers from the shoreline while beach seine is totally banned. The BSC caught by these gears are bycatch as these are not really crabbing gears. 
Table 4. Crabbing gears used by crabbers in different fishing grounds

\begin{tabular}{|c|c|c|c|c|c|c|c|c|c|c|}
\hline & \multicolumn{10}{|c|}{ Gears } \\
\hline $\begin{array}{c}\text { Fishing Ground } \\
\text { (Respondents) }\end{array}$ & $\begin{array}{c}\text { Bottom-set } \\
\text { Gill nets }\end{array}$ & \multicolumn{2}{|c|}{ Lift nets } & \multicolumn{2}{c|}{ Crab pots } & \multicolumn{2}{|c|}{ Gill nets and pots } & \multicolumn{2}{c|}{$\begin{array}{c}\text { Gill nets and } \\
\text { lift nets }\end{array}$} \\
\cline { 2 - 15 } & No. & $\%$ & No. & $\%$ & No. & $\%$ & No. & $\%$ & No. & $\%$ \\
\hline Ormoc Bay (19) & 19 & 100 & 0 & 0 & 0 & 0 & 0 & 0 & 0 & 0 \\
\hline San Pedro Bay (199) & 180 & 90 & 2 & 1 & 16 & 8 & 1 & 0.5 & 0 & 0 \\
\hline Leyte Gulf (195) & 171 & 88 & 19 & 10 & 5 & 2 & 0 & 0 & 0 & 0 \\
\hline Matarinao Bay (41) & 31 & 76 & 10 & 24 & 0 & 0 & 0 & 0 & 0 & 0 \\
\hline Maqueda Bay (250) & 162 & 65 & 23 & 9 & 60 & 24 & 3 & 1 & 2 & 0.8 \\
\hline TOTAL (704) & $\mathbf{5 6 3}$ & $\mathbf{8 0}$ & $\mathbf{5 4}$ & $\mathbf{8}$ & $\mathbf{8 1}$ & $\mathbf{1 1}$ & $\mathbf{4}$ & $\mathbf{0 . 5 7}$ & $\mathbf{2}$ & $\mathbf{0 . 2 8}$ \\
\hline
\end{tabular}

Crabbers from different areas use a particular gear type based on their respective tradition of BSC fishing. Eighty percent of the crabbers use bottom-set gill nets in crabbing (Table 4). Crabbers in Ormoc Bay mainly use bottom-set gill nets while crabbers from San Pedro Bay use crab pots and bottom-set gill nets. According to the crabbers in San Pedro Bay, they used to operate crab pots but livelihood assistance provided after ST Haiyan are mostly gill nets. In addition, bottom-set gill nets are easy to operate and do not need baits, unlike crab pots and crab lift nets. In Matarinao Bay, crabbers from Quinapondan use crab lift nets while crabbers from Salcedo operate with bottom-set gill nets. It was observed that crabbers from Maqueda Bay and Leyte Gulf use all types of gears (crab lift nets, bottom set gill nets, crab pots, and

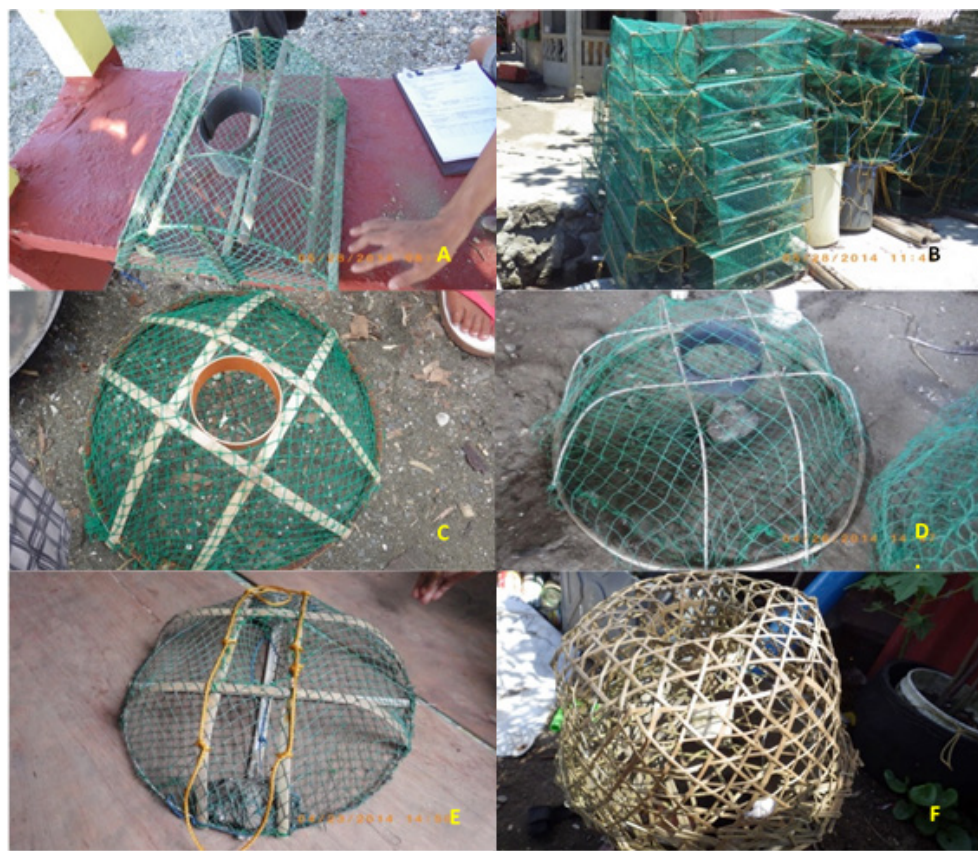

Figure 2. Different shapes and sizes of crab pots found from the different crabbing municipalities in the region: (A) Bombom, Catbalogan; (B) Yangta, Daram; (C) San Antonio, Basey; (D) Pangdan, Catbalogan; (E) San Jose, Tacloban; and (F) Naungan, Ormoc even trawls). Other considerations in their preference of crabbing gear include the cost and availability of materials and skills in making the gear.

\subsubsection{Crab pot}

The crab pot, locally known as panggal or timing, is a hand-crafted gear made of bamboo strips or tie wire and multifilament polyethylene netting with mesh sizes between $2.2-2.5 \mathrm{~cm}$. The net is wrapped around a bamboo framework to form a dome-shaped trap (Armada 1996). Other designs of crab pot do not use mesh nets, rather the trap is made

entirely of bamboo strips matted to form a domeshape contraption (Von Brandt 1984). Atop of the pot is a non-returning valve, made of either bamboo strips or plastic tube, which is large enough for the crabs to enter. Inside is a contraption for the bait (Armada 1996).

Table 5 lists the different types of crab pots used in some crabbing municipalities in the region. Based on the survey, crab pots in Leyte and Samar come in different sizes and shapes (Figure 2). Crabbers in San Pedro Bay, Maqueda Bay, and Leyte Gulf use 30 to 60 units of pots per line in one operation. 


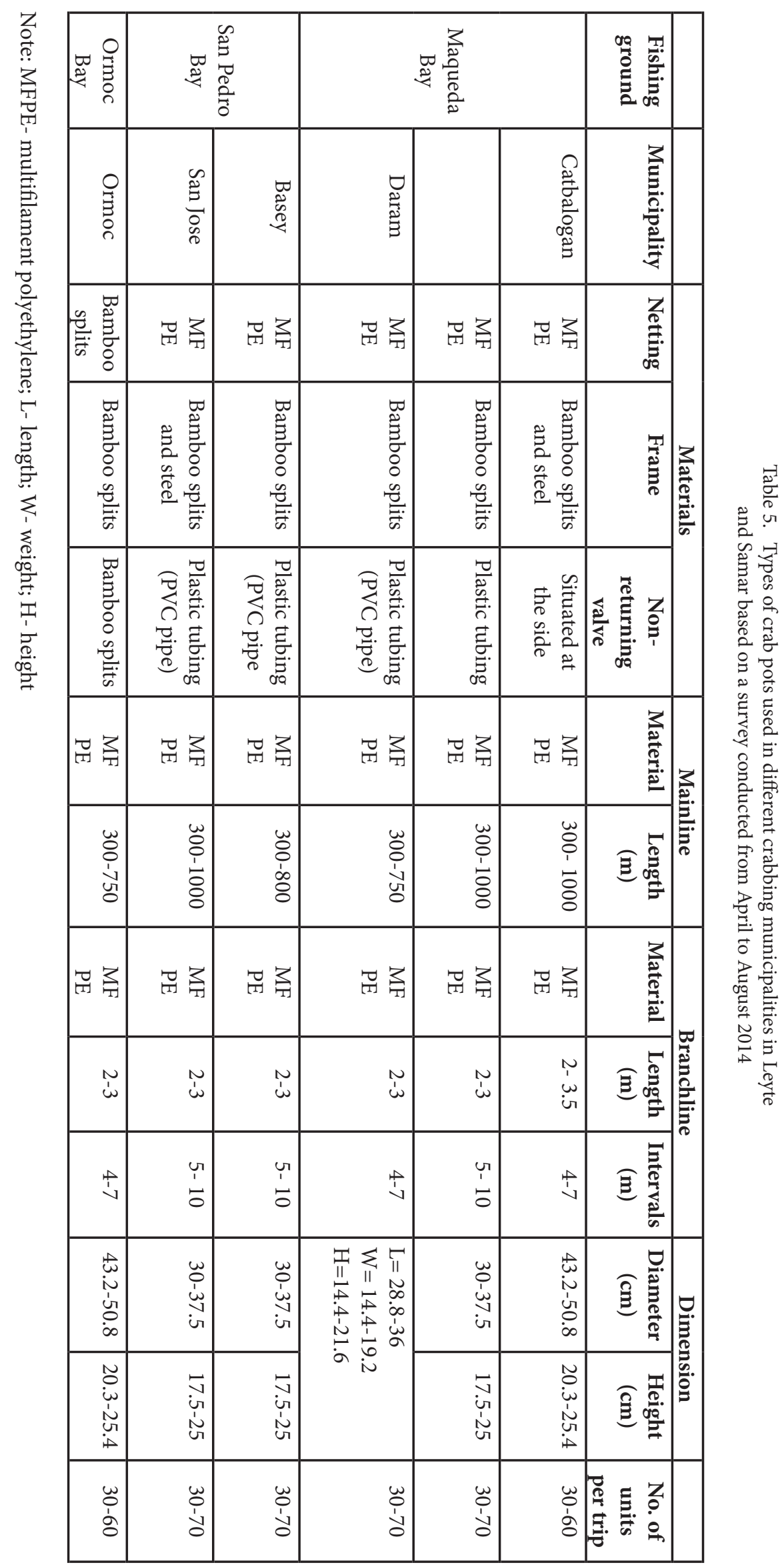




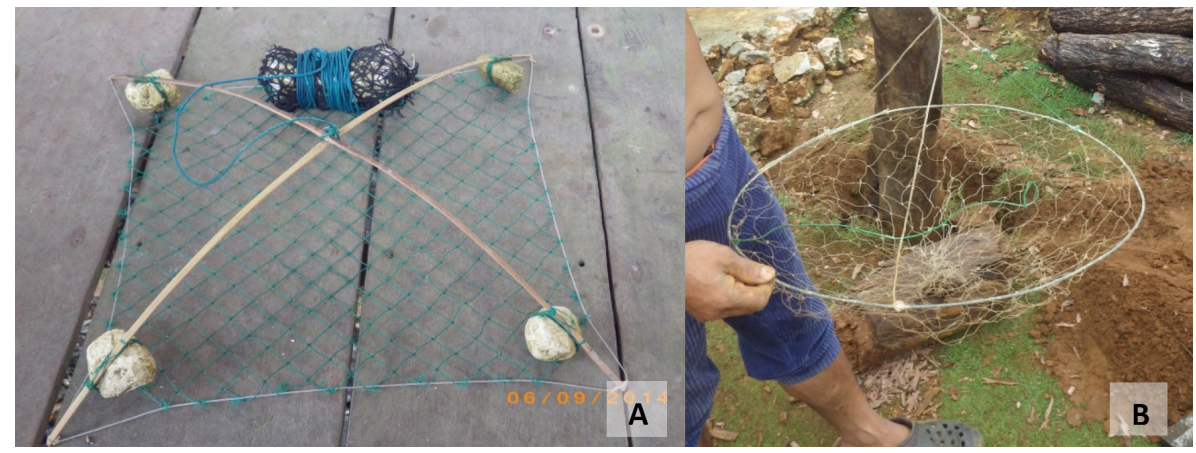

Figure 3. Types of crab lift nets: (A) the traditional crab lift net made of bamboo slats, polyamide netting, and frame; and (B) the modified crab lift net made of tie wire, nylon netting, and polyethylene rope

Commonly used baits are trash fish and bivalves such as slipmouth, green mussels (tahong) and brown mussels (piyong). Crab pots are usually deployed in waters 8-20 $\mathrm{m}$ deep. Setting operation varies according to location, water depth, and the number of pots used. Soaking time usually lasts from 10-12 hrs depending on the season. The crabbers usually deploy their pots at around 5:00 p.m. and haul them at around 4:00 to 5:00 a.m. the following day. Some crabbers in Catbalogan do multiple harvests within a day by alternately setting and hauling their pots. However, they have to own at least two sets of 30-70 pots to do so.

\subsubsection{Crab lift nets}

Crab lift nets, commonly known as bintol, are square-shaped or round gears made of monofilament polyamide netting, supported by two bamboo slats or polyethylene rope arched across the opposite side of the frame. The gear is attached to a long rope, usually $10 \mathrm{~m}$ long, to an improvised buoy (e.g. Styrofoam balls or box, plastic bottles, etc.). There are two main types of crab lift nets used for crabbing in Leyte and Samar (Figure 3). The traditional square-shaped crab lift net is made of monofilament polyamide netting, supported by two bamboo slats arched across the opposite corners of the square monofilament polyamide frame (Armada 1996). Another type of lift net is made up of nylon netting and tie wire instead of monofilament polyamide frame (Figure 4B). The second type has a round tie wire frame with two polyethylene ropes arched across two opposite sides of the circle. Generally, the bait hangs from the intersection of the bamboo slat or the polyethylene rope of the arches just above the net. Commonly used baits include trash fish, such as lawayan (Leiognathus splendens) and sapsap (Leiognathus bindus), and bivalves, particularly tahong (Perna viridis) and piyong (Mytilus $s p$ ). This gear is usually operated by a single crabber. The gear has to be monitored at a regular interval (Von Brandt 1984). Generally, crabbers in the region check each unit every 10 to 20 minutes after deployment for four to five hours during peak season but others would extend up to 10 hours to increase the catch on lean months. Crab lift nets usually have shorter soaking time (Vasquez Archdale et al. 2010). In Eastern Visayas, each crabber who use crab lift net usually owns 30 to 70 units of this gear. Crabbers usually operate this gear in waters approximately 4.5 to $10 \mathrm{~m}$ deep.

Crabbers using crab lift nets usually use nonmotorized boats. The gear is also easy and cheap to maintain compared to the pots. Some of the crabbers in the region prefer lift nets over pots because the gears are cheaper, lighter, easy to construct, more easily stacked on deck, and occupy less space as observed

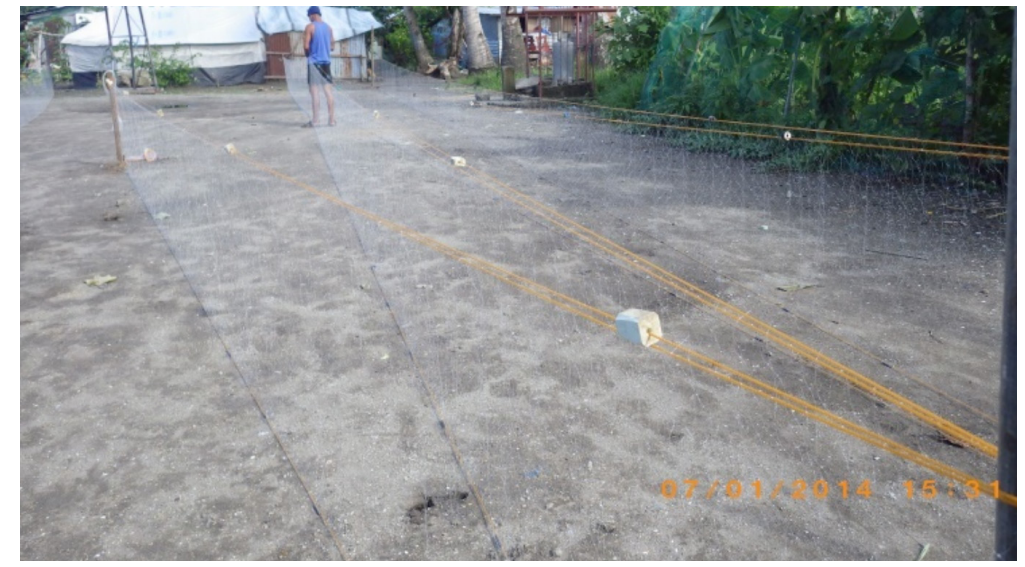

Figure 4. A crabber fixing a bottom set gill net in San Jose, Tacloban City 
in Japan (Vasquez Archdale et al. 2010). According to the crabbers, this gear catches more undersized crabs compared to the other gears. Most crabbers discourage the use of this type of gear to improve further the production of medium to large-sized crabs.

\subsubsection{Bottom-set gill nets}

Bottom-set gill net, locally known as pukot, consists of several panels of nylon, polyamide or kuralon nettings of different mesh sizes (Figure 4). Gill nets, in general, are long passive gears that are kept in a vertical position via the opposite forces of the float, which are attached to the head rope and the sinkers, which are attached to the footrope (Armada 1996). Moreover, the gear is divided into several segments or banata. The length of each segment varies across different locations and fishing grounds in the region. Crabbers from Maqueda Bay who use bottom-set gill nets usually have $100 \mathrm{~m}$ per segment while crabbers from Leyte Gulf use 200 m per segment. However, crabbers can make up to 30 segments, thus producing a 3000 or $6000 \mathrm{~m}$ of the gear. Most of the crabbers prefer Nylon No. 4 for making bottom-set gill nets. Bottom-set gill nets in Leyte and Samar consist of 50 meshes, vertically. Mesh size or mata ranges from 5 to $12.5 \mathrm{~cm}$. Crabbers cut the net by the number of mesh. Some divide the net by 20 , while others cut the nets from 9 to 12 mesh.

Crabbers usually set out to the sea between 4:00 p.m. to 5:00 p.m. and return to haul the net between 4:00 to 6:00 a. m. The setting operation can also vary depending on the season. During peak months, crabbers set their gears in the morning and haul it in the afternoon of the same day. The crabbers usually deploy the gears in deeper fishing grounds from 5 to $27 \mathrm{~m}$ deep. In Thailand, this gear is used outside the bay or in deeper parts to harvest larger crabs (Kunsook et al. 2014). Other than BSC, this gear traps other species of crabs (Portunidae), such as red crabs, mud crabs, flatfish (Bothidae), shrimps (Penaeidae), squid (Loliginidae), and other benthic fish.

Crabbers can go fishing with or without the company of another person. Majority of the crabbers in Leyte and Samar (52\%) operates without companions. However, others prefer the company of their relatives $(17 \%)$, sons $(15 \%)$, and non-related persons (4\%). Crabbers rarely bring their daughter to fishing (1\%). On the other hand, female crabbers are usually accompanied by their children. About $10 \%$ of the male crabbers in the region practice BSC fishing with their spouse. In Eastern Visayas, crabbers only bring one companion per operation. Male crabbers prefer the company of their children or spouse in order to retain or increase their family income rather than sharing it with non-related fishing partners.

Many crabbers adapt different harvesting techniques and even develop new ones to increase their harvesting capacity (Kunsook et al. 2014). A small proportion $(0.9 \%)$ of the crabbers in Leyte and Samar own two different gears and would use them at the same time. For instance, a crabber in Maqueda Bay owns both bottom-set gill nets and crab lift nets. Right after soaking the bottom-set gill nets, the crabber travels back near shore to practice lift net BSC fishing. On another note, a crabber from San Pedro Bay used crab pots along with the bottom-set gill nets. According to these crabbers, this strategy would help them increase their catch. In areas where different gears are used, particularly in San Pedro Bay, Maqueda Bay, and Leyte Gulf, crabbers opt to use certain crabbing gears at the same time or shift from one gear type to another depending on which gear catches the most crabs. However, this also entails additional expense/ capital investment.

Gill nets and pots are commonly deployed in the afternoon and hauled in the morning of the next day. After deploying the gears, most fishers leave the gear behind and only return to haul them. In contrast, some crabbers in Maqueda Bay, particularly in San Sebastian, Daram, and Zumarraga, watch over their bottom-set gill nets overnight or up to the hauling time. Crabbers report numerous instances where the bottom-set gill nets are stolen or hauled by anonymous culprits especially when the soaking time is done overnight apart from being accidentally destroyed by trawl fishers. This forced the crabbers in Maqueda Bay to guard their gears after setting.

Crabbers change their schedule of gear setting and hauling depending on the season. Sometimes, they deploy the gear such as bottom-set gill nets and crab pots at dawn and haul it in the afternoon of the same day. On lean months, some crabbers in Daram (Maqueda Bay) deploy the bottom-set gill nets into the sea and haul it after two days to ensure a higher catch.

A peculiar way of harvesting BSC wild stock was observed in Matarinao Bay. Some crabbers capture BSC with their own hands with the aid of an underwater flashlight. BSC fishing using this method is done in the evening until dawn. Crabbers tie their waist, wrist or ankle with a rope and the other end 
of the rope is tied to the boat. This is to make sure that the boat will follow the fisher wherever he goes. Equipped with goggles and an improvised underwater flashlight, the crabbers dive into the water, search for crabs, and capture BSC using bare hands. The catch is usually secured with a coconut leaf or rubber bands. Usually, crabbers prefer fishing in shallow waters ranging from two to four meters deep with muddy to rocky substrate. Crabbers who practiced this system are survivors of super typhoon and lived at temporary makeshift houses. Unable to buy new gears, these crabbers resorted to this old way of gathering BSC.

3.3 Awareness of regulatory measures regarding BSC fishery management

Table 6 shows the awareness of crabbers on regulatory measures regarding BSC fishery management. Crabbers in Matarinao Bay (95.1\%) have higher knowledge on policies regulating BSC catch compared to the crabbers in Ormoc (26.3\%). Among the crabbers who are aware of the BSC fishery management, $79.3 \%$ have information on size limitation while $84.3 \%$ have knowledge on the ban of catching or selling berried crabs. In terms of size limit, crabbers are aware that BSC with carapace length measuring less than $7.62 \mathrm{~cm}$ or 3 inches is classified as undersized or juvenile. The survey revealed that the majority of the crabbers in Leyte and Samar return the undersized crabs back into the water. However, there are crabbers, particularly in Maqueda Bay and Leyte Gulf, who still bring juveniles and are used for personal consumption or sold to local markets or direct buyers especially during lean months or when the catch rate is low. Meanwhile, most of the crabbers who have knowledge of the prohibition of catching and selling berried crabs release the undersized and gravid crabs back to the sea. Still, some crabbers continue to catch gravid crabs with carapace length ranging from $10.16-12.7 \mathrm{~cm}$ or $4-5$ inches. The medium to largesized gravid crabs are confined in an enclosure or fish pen in the coastal waters near the crabbers' homes. The berried crabs are restricted in the pens until it releases or hatches its eggs. Then, the crabs are sold along with other catch to the buyers. When catch rate is low especially during lean months, some crabbers directly sell the berried crabs, regardless of the size, to the middlemen, buying stations, or crab meat-picking plants in Eastern Visayas. There are also crabbers who return the berried crabs into the sea regardless of the size. Crabbers admit that the information on regulation regarding BSC fishery came from the
Table 6. Awareness of crabbers on local policies and plans for BSC fishery management

\begin{tabular}{|c|c|c|c|c|}
\hline \multirow{2}{*}{$\begin{array}{c}\text { Fishing ground } \\
\text { (Respondents) }\end{array}$} & \multicolumn{4}{|c|}{ Boat type } \\
\cline { 2 - 5 } & Motorized & \multicolumn{2}{|c|}{ Non-motorized } \\
\cline { 2 - 5 } & No. & $\%$ & No. & $\%$ \\
\hline $\begin{array}{c}\text { Ormoc Bay } \\
(19)\end{array}$ & 5 & 26.3 & 14 & 73.7 \\
\hline $\begin{array}{c}\text { San Pedro Bay } \\
(199)\end{array}$ & 106 & 53.3 & 93 & 46.7 \\
\hline $\begin{array}{c}\text { Leyte Gulf } \\
(195)\end{array}$ & 162 & 83.1 & 33 & 16.9 \\
\hline $\begin{array}{c}\text { Matarinao Bay } \\
(41)\end{array}$ & 39 & 95.1 & 2 & 4.9 \\
\hline $\begin{array}{c}\text { Maqueda Bay } \\
(250)\end{array}$ & 133 & 53.2 & 117 & 46.8 \\
\hline TOTAL (704) & $\mathbf{4 4 5}$ & $\mathbf{6 3 . 2}$ & $\mathbf{2 5 9}$ & $\mathbf{3 6 . 8}$ \\
\hline
\end{tabular}

information campaign and orientation conducted by the Bureau of Fisheries and Aquatic Resources (BFAR) in collaboration with their respective coastal municipal governments. It is important to note that these efforts by BFAR and the LGUs may have contributed to the awareness of the local crabbers regarding the status of the BSC fishery, and the measures and procedures being done to manage these resources.

For the crabbers who are not aware of any of the said regulatory measures have done similar practice with the crabbers who have knowledge of BSC catch regulations to improve the BSC wild stock. They also release juvenile, undersized, and berried BSC back into the water. However, there are also those that retain the undersized and berried which are sold or used for personal consumption.

Only two crabbers $(0.4 \%)$ from Ormoc knows that there is a closed season for harvesting BSC in the wild. When asked about the closed season, most crabbers, particularly full-time ones, do not favor the implementation of the said measure. It would be difficult for some crabbers to look for another way of living during closed season when the only livelihood they know is BSC fishing.

\subsection{Problems and Concerns}

Crabbers in Leyte and Samar are threatened by the depleting BSC wild stock. Over the past decades, the aggregate annual production of BSC wild stock in Eastern Visayas had been continuously declining (De la Cruz et al. 2015; Cabrales et al. 2015). Several factors 
contribute to the dwindling supply of BSC in Leyte and Samar fishing grounds, which includes overfishing and the prevalence of illegal fishing activities, among others. Overfishing due to increasing fishing effort and participation of fishers in crabbing activities are the main reasons why the wild stock face a continuous drop. Apart from increasing fishing pressure, the occurrence of illegal and unsustainable fishing practices such as dynamite fishing and hulbot-hulbot, sayad, and liba-liba, or collectively known as trawl fishing, also aggravate the dwindling volume of BSC by destroying its natural habitat and breeding grounds. The crabbers also see the lack of implementation of policies and local ordinances regarding local fisheries management as a major contributor to the dropping trend of the wild stock. Furthermore, there is also a need for scientific and periodic evaluation and monitoring on the status of the BSC wild stock in the different fishing grounds in the Eastern Visayas region. Moreover, the dwindling BSC production warrants a detailed study on the biology and seasonality, among others, to determine what is really causing the decline in the BSC population, and to search for appropriate procedures to improve the BSC population in the wild or in grow-out cultures.

\subsection{Suggestions to improve the BSC fishery in Leyte} and Samar

\subsubsection{More studies focusing on the BSC and the crabbers}

While it is true that the number of BSC is declining in the wild, there has been minimal information on the population, biology, seasonality, and fishery of the BSC in Eastern Visayas. The depleting wild stock warrants further study on the biology, population, and fishery of the BSC, which could be used by policymakers and local legislators in formulating management plans, procedures, and regulations that will address issues and concerns regarding BSC fishery and the individuals dependent on it. Studying the biology and population dynamics of the BSC will help determine the peak season and lean months in the different fishing grounds in Leyte and Samar. Moreover, periodic evaluation and monitoring of the BSC wild stock will help identify the breeding season, which can determine when to close temporarily the opportunity for crab fishing specific to the different fishing grounds in Leyte and Samar. There is also a need to gather available data on BSC studies, monitoring, and evaluation in the region, which can be used in framing appropriate BSC fishery management plan to reverse the effects of unsustainable fishing practices in the region. Additionally, scientific studies will also help determine whether re-stocking in BSC depleted fishing grounds would really enhance the stocks or not. Meanwhile, it is expected that the government agencies, nongovernment organizations (NGOs), the LGUs, and the academe work together in conducting research related to the fisheries and biology of the BSC and use the data in generating science-based policies and local legislation, and in framing an effective management plan for these resources.

It is also important to study the social, economic, and demographic situation of the crabbers in the region in order to formulate plans and programs that will provide appropriate and necessary assistance, which will aid in alleviating the poor living conditions of this sector.

\subsubsection{Use of sustainable gears and fishing practices}

Confronted with the depleting BSC supply, the crabbers resort to unsustainable fishing practices in order to increase their production, which exacerbates the present status of the BSC wild stock. These desperate measures are demonstrated in some of the crabbers' confession to bring juvenile, undersized and berried crabs to sustain their income or the daily food consumption of their family. However, some crabbers urge others to release berried crabs back into the water or allow these crabs to hatch its eggs before selling them. They also return undersized BSC back into the sea. In choosing gears, the crabbers suggest using bottom set gillnets and crab pots over crab lift nets. Apart from higher operational cost, because of the bait, lift nets catch undersized crabs based on the observation of the crabbers in Leyte and Samar. While the crab pots also use baits, the BSC caught are alive and the crabber can release undersized, juvenile and berried crabs back to the sea uninjured. To avoid entangling juveniles, when harvesting medium to large-sized BSC, it is better to use bottom set gill nets with bigger mesh opening (10 to $13 \mathrm{~cm}$ ) as it is cheaper to maintain and require lower operational coast.

\subsubsection{Dissemination and implementation of BSC regulatory measures}

Majority of the crabbers in the region suggest that policies, ordinances, or certain management 
measures should be implemented in all crabbing municipalities to sustain and enhance the BSC wild stock in Eastern Visayas (De la Cruz et al. 2015). However, most of the crabbers interviewed in Leyte and Samar know only minimal albeit crucial points in the Philippine Blue Swimming Crab Management Plan (BSCMP). This information includes size limitation, a ban on catching and selling berried crabs, and the implementation of a closed season for wild stock harvest. The BSCMP was developed by the Department of Agriculture (DA) through BFAR to improve the BSC wild stock volume in the Philippines. Noting this reaction from the crabbers, BFAR along with LGUs should intensify the dissemination of the said plan to reach more locals, most especially the crabbers. This management plan should also be reinforced by local ordinances prior to implementation (De la Cruz et al. 2015). Furthermore, the crabbers suggest the strict implementation of trawl ban and dynamite fishing particularly in BSC wild stock depleted fishing grounds.

Government agencies, LGUs, and other concerned organizations should take advantage of the modern technology or the use of social networking sites to reach a broader network of individuals in the conduct of information dissemination and monitoring of BSC fishery in the region. For instance, the Eastern Visayas Center Crustacean Research and Development (EVCCRD) created an infographic based on a city ordinance regulating BSC catch in Catbalogan and uploaded it to their Facebook account. This particular strategy will help reach a broader spectrum of audiences such as the young, other concerned entities, and even government officials. There is no assurance, however, that there will be a direct effect on enhancing the population of BSC in the wild but it will increase the awareness on the status of the BSC not just among crabbers but as well as other concerned individuals in the region and the country.

\subsubsection{Alternative livelihood opportunities}

Another way to increase the BSC wild stock volume is to reduce fishing pressure by providing alternative sources of income to crabbers such as aquaculture. BFAR is offering livelihood projects to fishers who wish to shift from being fish hunters to fish farmers. The campaign to promote the aquaculture industry aims to satisfy the food requirements and ease the pressure from already distressed seas (Labro 2011). In terms of value, aquaculture products contributed nearly $53.1 \%$ to the Philippines' fisheries production in the first quarter of 2018 (Philippine
Statistics Authority 2018). According to the January to March 2018 Fisheries Situation Report, most of the production comes from the farming of milkfish (98.28\%), oyster $(91.44 \%)$, carp $(89.01 \%)$, tilapia $(88.69 \%)$, seaweed $(84 \%)$, and mussel $(54.18 \%)$. On the other hand, LGUs must also look for ways to support the needs of the crabbers and their family. This could be done by establishing mutually beneficial linkages and partnerships with other government agencies, such as BFAR, TESDA, and DA, and offer the crabbers and their family with free skills training, livelihood, and scholarship grants for the children. Farming and other technical courses can be learned through vocational courses. In this way, the economic and educational status of the crabbers and their children could be improved.

\section{CONCLUSION AND RECOMMENDAT ION S}

Generally, the crabbers and their family in Eastern Visayas remain poor because of their lack of formal education, which limits them from engaging in other types of livelihood that will increase their income. The majority of the income, which comes from BSC fishery, is barely enough to support the basic needs of the family. While some of the crabbers and their family members have other income sources, these are not adequate to support their other needs, particularly education. With the dwindling BSC supply, the socioeconomic situation of the crabbers will not improve, and while management measures to conserve the BSC resources are in place, the increasing fishing pressures from crabbers will continue to impact on the resource. Closed seasons can be an effective means to allow the resource to recover but this should be coupled with assistance to the crabber families who will be displaced in the process, otherwise, this measure will not work. More permanent measures to reduce BSC fishing pressure must be developed and this could include ensuring support for education, skills training, and alternative livelihood to members of the crabbing families to take them away from crabbing. Strict implementation of the BSCMP must also be observed by the LGUs along with the other fishery laws and ordinances to ensure the sustainability of the coastal fisheries. Widespread information campaign must be done to orient/educate the people on the importance of the BSCMP for the sustainability of the BSC fishery. In addition, LGUs should enforce the protection of BSC natural habitats and breeding grounds to improve the population of BSC. 
The lack of biological information on BSC is another a factor that affects the effective management of the BSC fishery. There is a need to know more about the BSC biology and seasonality, and to assess the BSC stocks. Further investigation into the social, economic, and demographic conditions of the crabbers is also needed for a more effective and appropriate response to their condition, as well as seek other strategies that will alleviate the socio-economic status of crabbers and improve the BSC production.

\section{A C K N O W L E D G M E T}

This study was funded by DOST-PCAARD. The research team would like to thank all the crabbers, buyers, traders, and processors who agreed to be interviewed for this study.

\section{R E F E R E N C E S}

ACTED. 2014. Food security and livelihoods assessment report: Leyte and Eastern Samar, Philippines [Internet]. [retrieved 2014 Oct 13, cited 2015 May 28] Available from: https:// www.humanitarianresponse.info/sites/www. humanitarianresponse.info/files/assessments/ ACTED\%20AMEU\%20Food\%20Security\%20 and $\% 20$ Livelihoods $\% 20$ Assessment $\% 20$ Report $\% 20$ Leyte $\% 20$ and $\% 20$ Eastern $\% 20$ Samar\%20-\%20FINAL.pdf

Armada NB. 1996. Capture fisheries of San Pedro Bay, Philippines. Technical Report on the Resource and Ecological Assessment of San Pedro Bay, Philippines. Fishery Sector Program: U.P. Visayas Foundation Incorporated.

Asian Development Bank (ADB). 2009. Poverty in the Philippines: causes, constraints and opportunities. ISBN 978-971-561-857-1. 54p.

Asian Development Bank (ADB). 2018. ADB Briefs: social protection brief reducing youth not in employment, education, or training through jobstart Philippines. ISSN 2218-2675 (electronic). 1pp.

Butcher JG. 2004. The closing of the frontier: A history of the marine fisheries of Southeast Asia c. 1850-2000. Institute of Southeast Asian Studies, Singapore.
Cabrales PS, Rayucal JT, Manoza AG. 2015. Crabbing into an uncertain future: The blue swimming crab fisher in coastal town of Eastern Philippines. The Countryside Development Research J. 3(1):1-12.

De Guzman AB, Sumalde ZM, Colance MDB, Ponce MFV, Rance GMS. 2016. Reef gleaning in the Philippines: Does it contribute to poverty alleviation and nutrient security? EEPSEA Policy Brief No. 2016. PB10. 4pp

De la Cruz MT, De la Cruz JO, Tan IL, Ruizo EK. 2015. The blue swimming crab (Portunus pelagicus) fishery of Easten Visayas, Philippines. UPV J. of Nat. Sci., 20(1): 25-45.

Del Norte-Campos AGC, Villarta KA, Panes JB, Declarador M. 2004. Catch and catch rates of the blue swimming crab (Portunus pelagicus L.) in various fishing frounds in Panay Island. UPV J. Nat. Sci., 9(1): 79-86.

FAO. 2013. Fisheries Aquaculture - Aquatic species: Potunus pelagicus. Available at: http://www.fao. org/fishery/species/2629/en

Gadhavi MK, Kardani HK, Pathak R, Prajapati PC, Vachhrajani KD. 2013. Impact of trawl fish ban on artisanal brachyuran crab fishery in and around Sikka, Gulf of Kutch, Gujarat, India. Res. J. of Animal, Vet. and Fish. Sci., 1(1): 22- 27.

Germano BP, Melgo JF. 2003. The population, reproductive and fishery biology of the blue crab, Portunus pelagicus, in Leyte and Samar and management implications. UPV J. of Nat. Sci. 8 . 63-82.

Ingles JA. 2004. Status of the blue crab fisheries in the Philippines. In: Turbulent Seas: The status of Philippine Marine Fisheries. Coastal Resource Management Project, Cebu City, Philippines. p. 47-52.

Kunsook C, Gajaseni N, Paphavasit N. (2014). A Stock assessment of the blue crab Portunus pelagicus (Linnaeus, 1758) for sustainable management in Kung Krabaen Bay, Gulf of Thailand. Trop. Life Sci. Res. 25(1): 41-59.

Labro V. 2011. Aquaculture gets a boost in Samar. Philippine Daily Inquirer [Internet]. [cited 2017 April 5]. Available from: http:// 
$\mathrm{meco} \cdot \mathrm{ph} / \mathrm{mecog} / \mathrm{index} \cdot \mathrm{php}$ ? option $=\mathrm{com}_{-}$ content\&task $=$ view\&id $=336 \&$ Itemid $=1$

Lai JCY, Ng PKL, Davie PJF. 2010. A revision of the Portunus pelagicus (Linnaeus, 1758) species complex (Crustacea: Brachyura: Portunidae), with the recognition of four species. The Raffles Bulletin of Zoology 58(2): 199---237.

Meniano SQ. 2016. Poverty incidence in Region 8 worsens from 2012 to 2015 survey. Bicol Today. Available from; http://bicoltoday. com/2016/05/16/poverty-incidence-in-region8-worsens-from-2012-to-2015-survey/

Philippine Statistics Authority (PSA). 2016. The annual labor and employment statistics estimates for 2016. Available from: https:/psa.gov.ph/ content/2016-annual-labor-and-employmentstatus .

Philippine Statistics Authority (PSA). 2018. January - March 2018 Fisheries Situation Report. ISSN 2012- 0400. 34p.
Rhodes A, Lipton D, Shabman L. 2001. Technical Report: A socio-economic profile of the Chesapeake Bay commercial blue crab fishery.

Romero FG, Juinio MAM, Ingles JA, Campos WI. 2009. Catch rates and size structure of blue swimmer crab, Portunus pelagicus (L.), in the Visayan Sea.

Siason IM. 2004. Women in fisheries in the Philippines. In Turbulent seas: the status of Philippine marine fisheries. Department of AgricultureBureau of of Fisheries and Aquatic Resources. Coastal Resources Management Project. Cebu City, Philippines. CRMP. Document No: 02CRM/2004. ISBN: 971-92753-4-0. p. 144-149.

Vasquez Archdale M, Anasco CP, Nakagawa A. 2010. Liftnets compare favorably with pots as harvesting fishing gear for invasive swimming crabs. J. of Fish. Aqua. Sci., ISSN 1816-4927.

Von Brandt, A. 1984. Fish Catching Methods of the World. 3rd Ed., Fishing News Book. Ltd., UK. 